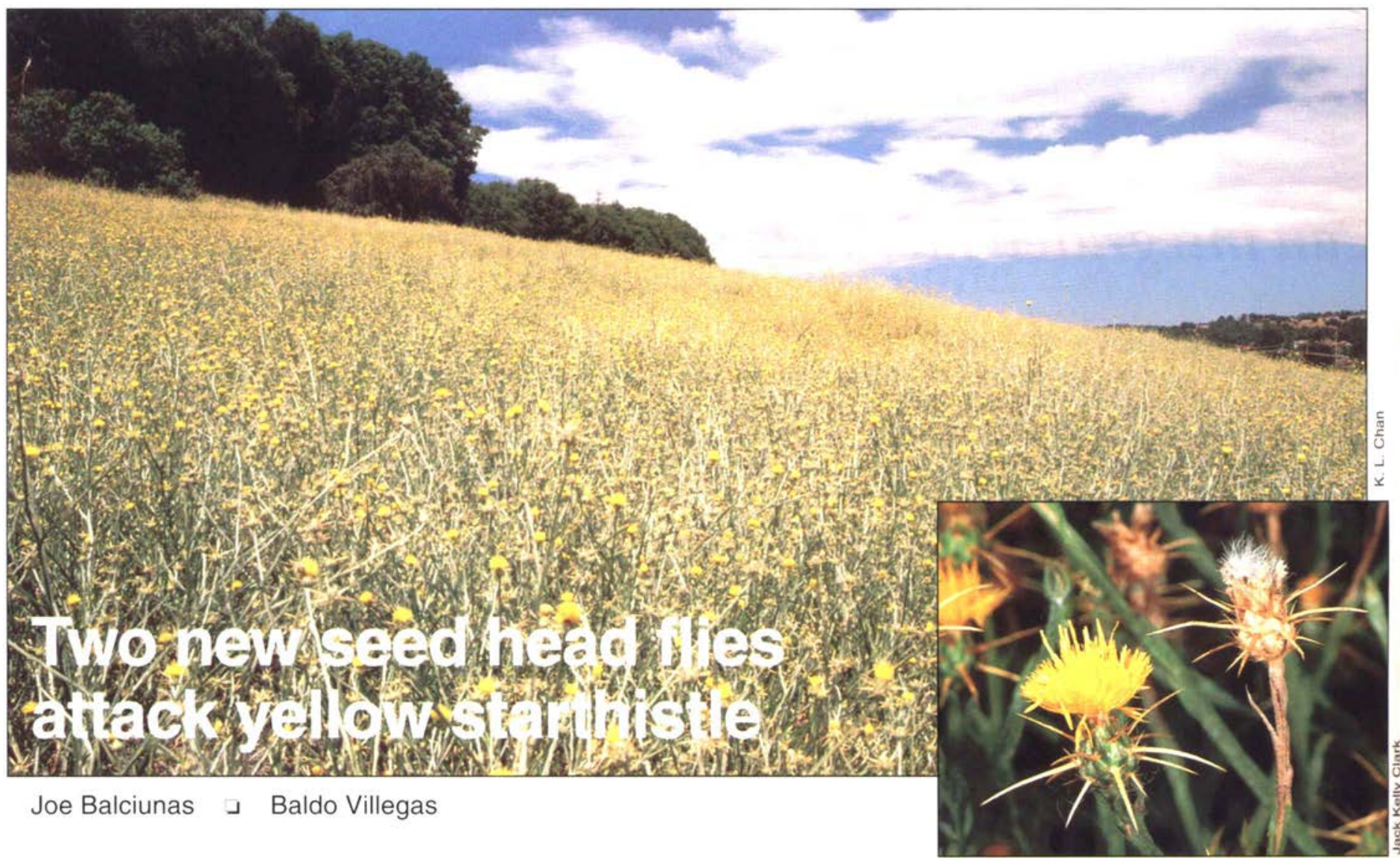

Six species of overseas insects have been approved for release as biological control agents of yellow starthistle, California's most pervasive weed. Previously, four biocontrol insects were known to be established in California; we now confirm the establishment of the peacock fly, as well as the accidentally introduced false peacock fly. Remarkably, the false peacock fly is significantly more widespread and more effective against yellow starthistle than the peacock fly - or any other biocontrol insect to date. However, since the false peacock fly is not an approved agent, we will await completion of our ongoing field and laboratory assessments of this fly's safety to crops and native plants before recommending use of this promising fly as a biological control agent.

While California's diverse habitats support hundreds of invasive weed species, probably none is more widespread nor pernicious than yellow starthistle (Centaurea solstitialis L.) Yel- low starthistle replaces desirable vegetation, in both natural and managed settings. In natural settings, it diminishes recreational values, and dense stands of this invasive exotic can reduce biodiversity and help carry wild fires. Within California's agricultural community, yellow starthistle most severely impacts ranchers. While young yellow starthistle shoots can be grazed by cattle, the sharp spines of older plants deter feeding, thereby greatly reducing the forage value of hundreds of thousands of acres for most of the year. Yellow starthistle can be toxic to horses that feed on it, causing a fatal neurological disorder called "nigropallidal encephalomalacia" (Cordy 1978). Starthistle removal also increases herbicide and labor costs for other agricultural enterprises, such as vineyards and orchards.

Yellow starthistle is native to the eastern Mediterranean region of Eurasia, and was introduced into California more than 150 years ago (Maddox and Mayfield 1985). It is now the state's most widespread weed. The infested area increased from an estimated 1.2 million acres in 1958 to 7.9 million acres in 1985 (Maddox and
Yellow starthistle, one of California's more pernicious weeds, infests this field in Nevada County.

Mayfield 1985). Yellow starthistle's logarithmic range expansion continues. A 1997 survey by California Department of Food and Agriculture (CDFA) found this weed in $42 \%(\mathrm{n}=$ 1,935 ) of California's 4,638 townships - each 6 by 6 square miles - and in $22 \%(1,019$ townships $)$ the infestations are reported as "high" (Pitcairn et al. 1998a). "High" abundance was defined as being, at a minimum, several miles of dense roadside infestation.

Widespread exotic pests, such as yellow starthistle, are obvious targets for classical biological control, in which natural enemies of a pest are imported from its native territory. Potential biocontrol agents for weeds are carefully selected and screened in extensive tests to ensure their safety. Prior to release, an array of federal and state agencies review the host range tests and other information about the proposed agent; formal approval for release must be granted by the U.S. Department of Agriculture's Animal and Plant Health Inspection 
Service (USDA-APHIS), as well as by the state where the release will take place.

This classical biological control approach has been used against more than 100 weed species worldwide. California has benefited greatly from the successful biological control of invasive plants such as Klamath weed (Hypericum perforatum), tansy ragwort (Senecio jacobaea), and puncture vine (Tribulus terrestris) (Julien 1992). Overseas surveys to locate potential biocontrol agents for yellow starthistle began in Europe 40 years ago, and, to date, six insect species have been approved and released in the United States for control of this invasive weed (table 1). All six species attack the flowers or seeds of yellow starthistle.

\section{The peacock fly}

The third seed head fly to be approved for release was the peacock fly, Chaetorellia australis Hering, whose larvae feed inside the seed head of yellow starthistle, destroying most of the developing seeds. The mature larvae overwinter in the old heads, with the adults emerging in the spring. Females oviposit on maturing buds. Releases of peacock flies, reared from yellow starthistle heads shipped from Greece to the USDA Agricultural Research Service (ARS) quarantine facility in Albany, Calif., began in 1988. By 1994, peacock fly had been released at 14 sites in California, Idaho, Oregon and Washington, but establishment was confirmed only at two sites that year, one each in Oregon and Washington, and at one of the Idaho sites in 1995 (Turner et al. 1996). Establishment of this fly was not observed at any of the six California sites (Turner et al. 1996). At the three sites (in Idaho, Oregon and Washington) where the peacock fly did establish, bachelor's button, Centaurea cyanus, was widespread. Bachelor's button is another exotic annual, closely related to yellow starthistle, that is invasive in the Pacific Northwest. It was theorized that the early-blooming bachelor's button flowers were acting as an alternate host until yellow starthistle blossomed some weeks later (Turner et al. 1996).

Buoyed by these successful establishments, we renewed the colonization effort for the peacock fly in California, with releases at 7 sites in 7 counties in 1995, and 15 more releases in 12 counties in 1996. Sites containing both bachelor's button and yellow starthistle were given the highest priority. In California, bachelor's button has naturalized primarily in higher elevation sites in the northern part of the state. Second priority was given to sites with early-blooming yellow starthistle. All flies released (except one sample from bachelor's button) were those that emerged from yellow starthistle heads collected at the Merlin, Ore., site.

During our surveys at the end of 1995, populations of Chaetorellia flies were found at multiple locations in Humboldt and Trinity counties in Northern California. The fly populations in these counties were so large and widespread that we surmised that

TABLE 1. Overseas insects released in California as approved biological control agents for yellow starthistle (YST)

\begin{tabular}{lcl}
\hline \hline Biocontrol agent & Date of release & Status \\
\hline $\begin{array}{l}\text { Urophora jaculata } \\
\text { (Diptera: Tephritidae) }\end{array}$ & 1969 & Never established in United States \\
$\begin{array}{c}\text { Urophora sirunaseva } \\
\text { (Diptera: Tephritidae) }\end{array}$ & 1984 & $\begin{array}{c}\text { Widely established, present at most YST } \\
\text { infestations in state }\end{array}$ \\
$\begin{array}{c}\text { Bangasternus orientalis } \\
\text { (Coleoptera: Curculionidae) }\end{array}$ & 1985 & $\begin{array}{c}\text { Widely established, present at most YST } \\
\text { infestations in state }\end{array}$ \\
$\begin{array}{c}\text { Chaetorellia australis } \\
\text { (Diptera: Tephritidae) }\end{array}$ & 1988 & $\begin{array}{c}\text { Not known to have established in state } \\
\text { prior to this study }\end{array}$ \\
$\begin{array}{c}\text { Eustenopus villosus } \\
\text { (Coleoptera: Curculionidae) }\end{array}$ & 1990 & $\begin{array}{c}\text { Well established, being redistributed } \\
\text { by California Dept Food \& Ag }\end{array}$ \\
$\begin{array}{c}\text { Larinus curtus } \\
\text { (Coleoptera: Curculionidae) }\end{array}$ & 1992 & Established at a few release sites in state \\
\hline
\end{tabular}




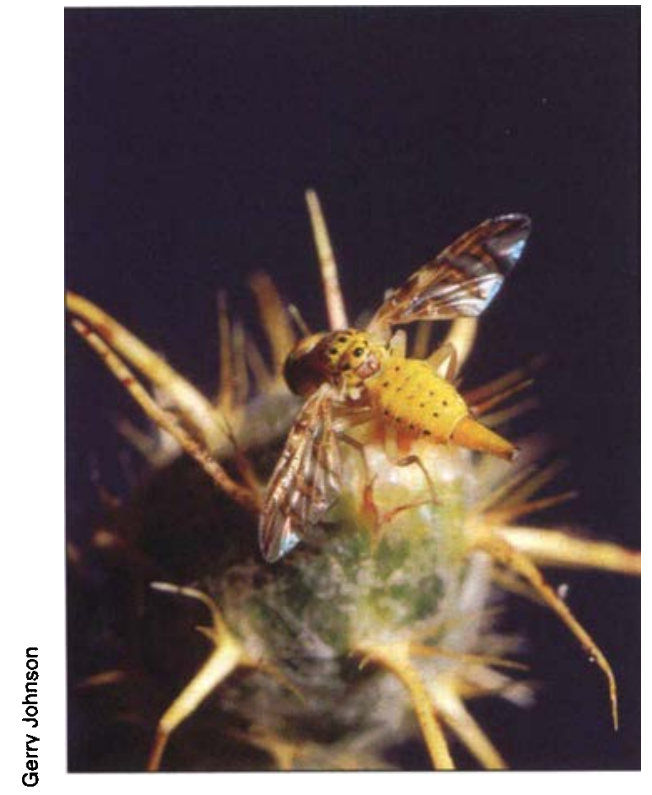

Above, the false peacock fly, Chaetorellia succinea. Below, the faise peacock fly (left), and the "true" peacock fly, Ch. australis (right). Note the extra spot on the upper left side of the thorax of the false peacock fly.

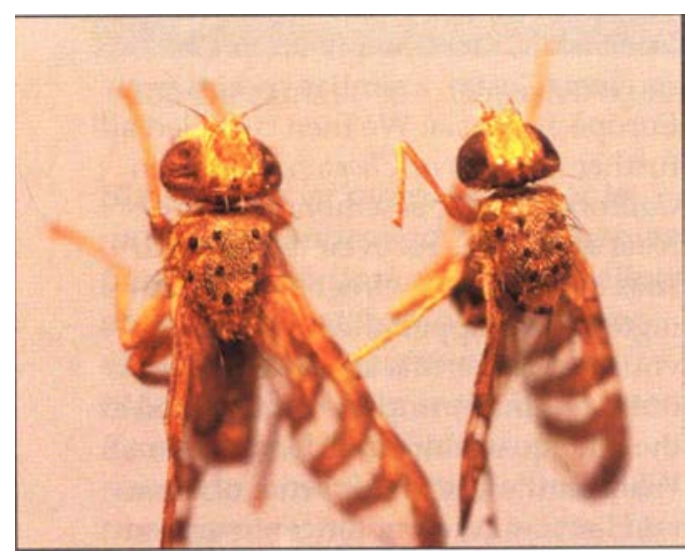

we will refer to $C h$. succinea as the false peacock fly.

\section{Origin of the false peacock fly}

Like all the yellow starthistle biocontrol agents, the shipments of Chaetorellia had passed through the USDA-ARS quarantine containment facility in Albany. There, adults were allowed to emerge from the heads, parasites and other insects were removed, then the Chaetorellia were collected and transferred to the release site. We collated all the shipment records for Chaetorellia flies at the Albany quarantine, and assembled all the voucher specimens that had been retained at the quarantine from these shipments. We also examined voucher specimens retained by our cooperators in Idaho, Oregon and Washington.
The quarantine records showed that there had been 17 shipments of Chaetorellia-infested heads from Greece during 1986-1994. Flies emerging from nine of these shipments of yellow starthistle heads were eventually released in four states. There were 43 voucher specimens from these release shipments, and our cooperators in other states also had retained a similar number. We identified the voucher specimens, and had representative specimens confirmed by Chaetorellia expert White. This allows us to put forth the following probable scenario for the introduction of the false peacock fly. Chaetorellia australis was the only fly present among the voucher specimens from all these shipments, except for a 1991 shipment of yellow starthistle heads collected in Oreokastro, Greece. That shipment contained both the true peacock fly, $\mathrm{Ch}$. australis, and the false peacock fly, $\mathrm{Ch}$. succinea. The presence of the false peacock fly contaminating this shipment was not detected at the Albany quarantine, and the flies that emerged were sent and released at the Merlin, Ore., site. Both flies became established at this site, and a variety of agencies from several states subsequently used flies collected from this Merlin site in their attempts to control yellow starthistle in their own regions. It is one of the responsibilities of a quarantine to assure that only the approved agent is released. However, when hundreds of live insects must be examined, as was the case in 1991, without killing or damaging the insects slated for release, a cryptic species might be overlooked. The presence of $\mathrm{Ch}$. succinea at the Oreokastro, Greece, site had not been observed, and was not even suspected.

\section{Distribution of Chaetorellia flies}

Once we were aware of the presence of a second Chaetorellia fly in California, we started extensive surveys to determine the distribution of both species. During 1996, we surveyed 207 sites in California, and recovered Chaetorellia flies from all 15 of the 1995-96 release sites, and also 6 other sites where it had not been released. During 1997 and 1998, we surveyed
207 and 268 sites, respectively, in California. We revisited not only the original Chaetorellia release sites, but also searched yellow starthistle along probable flyways, such as major river systems or highways. At each site, we systematically swept the yellow starthistle heads with an insect net (usually 20 sweeps), and, for at least one site in each county, collected heads that had recently finished flowering. The latter were held in emergence containers in the laboratory until the flies stopped emerging from them, about 1 year later. Over the last 4 years, we collected more than 700 samples from over 450 California sites (fig. 1). We recovered "true" peacock fly at four release sites, and at 20 additional, scattered sites in seven counties, all of which have bachelor's button in addition to yellow starthistle. On the other hand, the false peacock fly is well established at 415 of our sample sites, and is spreading rapidly. We recovered it from 9 counties in 1995, from 21 counties in 1996, 34 in 1997, and from 44 counties during 1998. We anticipate that the false peacock fly will continue to expand its geographic range. We will continue to monitor how completely its range will overlap with its host, yellow starthistle.

\section{Impact on yellow starthistle}

How much damage is the false peacock fly inflicting on yellow starthistle? CDFA, ARS, Oregon Department of Agriculture, and university scientists in several states are assessing the long-term effects the false peacock fly will have on established yellow starthistle infestations. CDFA recently found that at one site in Amador County, $36 \%$ of the yellow starthistle heads had been attacked by false peacock fly, and the heads with flies had $78 \%$ less seed (Pitcairn et al. 1998b). During 1998, assisted by colleagues in other states, we conducted similar studies at more than 50 sites in California, Oregon and Washington. These samples are still being processed, but we are recording similar seed reductions, although at some sites more than $50 \%$ of the heads have been attacked. By contrast, ento- 
mologist Gary Piper at Washington State University has studied the damage caused by $\mathrm{Ch}$. australis, the true peacock fly, for 6 years at a site in Colfax, Wash., where Ch. succinea still does not occur. He has never recorded more than $5 \%$ of the yellow starthistle heads as being attacked by the peacock fly (G. Piper, personal communication)

Since yellow starthistle is an annual that produces seeds copiously, creating a persistent seed bank, it will take many years to determine the impact false peacock flies are having on yellow starthistle infestations in California. However, our preliminary observations of the damage this fly is causing to individual heads and plants of yellow starthistle indicate that $C h$. succinea should contribute to the eventual control of yellow starthistle at sites where it establishes. Once this fly arrives at a site, its populations can quickly increase, and a large percentage of yellow starthistle heads are attacked by the larvae. A single larva, while feeding inside the maturing seed head, will destroy most, but usually not all, of the developing seeds. In addition, it has multiple generations per year, and its attack is sustained throughout yellow starthistle's lengthy flowering period in California. Frequently, at many sites in California, but less often in northern states, yellow starthistle continues to flower until late summer or early autumn. This is very important, as none of the other approved and established yellow starthistle biocontrol agents commonly attack these late-blooming yellow starthistle flowers.

\section{Damage to other plants?}

The false peacock fly is not an "approved" biological control agent. It has not been fully tested to determine if it will attack plants other than yellow starthistle. Brief host-range tests were conducted in Europe, when this fly was still known as a "semi-species" of Chaetorellia carthami. The investigators (Sobhian and Zwölfer 1985) found that it would not attack safflower, Carthamus tinctorius, a close relative of yellow starthistle. However, they were able to hybridize Ch. succinea with $\mathrm{Ch}$. carthami, a minor pest of safflower in the Middle East. They therefore recommended against importing it into the United States, especially since, at that time, there were many other potential agents to consider. $\mathrm{Ch}$. carthami is not known to be present in the United States. Prudence, however, dictates that we evaluate the host range of false peacock fly, especially in respect to potential damage it may cause to safflower or native Cirsium thistles. We and our colleagues in other states are currently evaluating the host range of false peacock fly. We expect to complete our evaluations during 1999. Preliminary analyses of the first 2 years of field observations and laboratory tests indicate, however, that damage to commercial safflower varieties in California by this accidentally introduced false peacock fly is improbable, but if it occurs, damage will be, at the most, minuscule.

J. Balciunas is Research Entomologist and Yellow Starthistle Biocontrol Project Leader at the Exotic $\mathcal{E}$ Invasive Weed Research Unit, USDA-ARS Western Regional Research Center, Albany; and a member of the UC Berkeley Center for Biological Control; B. Villegas is Associate Environmental Research Scientist, California Department of Food and Agriculture, Biological Control Program, Sacramento.

\section{References}

Cordy DR. 1978. Centaurea species and equine nigropallidal encephalomalacia. In: Keeler RF, Van Kampen KR, James LF (eds.). Effects of Poisonous Plants on Livestock. New York, Academic Press. p 327-36. Julien MH (ed.). 1992. Biological Control of Weeds: A World Catalogue of Agents and Their Target Weeds, 3rd ed. Wallingford, UK: $\mathrm{CAB}$ International. $186 \mathrm{p}$.

Maddox DM, Mayfield A. 1985. Yellow starthistle infestations are on the increase. Cal Agr 39(11-12):10-2.
Pitcairn MJ, O'Connell RA, Gendron JM. 1998a. Yellow starthistle: Survey of statewide distribution. In: Woods DM (ed.). Biological Control Program Annual Summary, 1997. Sacramento: California Department of Food and Agriculture, Division of Plant Industry. p 64-5.

Pitcairn MJ, Joley DB, Woods DM, Popescu V. 1998b. Impact of Chaetorellia succinea on yellow starthistle, Centaurea solstitialis, in California. In: Woods DM (ed.). Biological Control Program Annual Summary, 1997. Sacramento: California Department of Food and Agriculture, Division of Plant Industry. p 56-7.

Sobhian R, Zwölfer H. 1985. Phytophagous insect species associated with flower heads of yellow starthistle (Centaurea solstitialis L.). Zeitschrift fuer angewandte Entomologie 99:301-21.

Turner CE, Piper GL, Coombs EM. 1996. Chaetorellia australis (Diptera: Tephritidae) for the biological control of yellow starthistle, Centaurea solstitialis (Compositae), in the western USA: establishment and seed destruction. Bull Entomol Res 86: 177-82.

White IM, Marquardt K. 1989. A revision of the genus Chaetorellia Hendel (Diptera:

Tephritidae) including a new species associated with spotted knapweed, Centaurea maculosa Lam. (Asteraceae). Bull Entomol Res 79:453-87. 